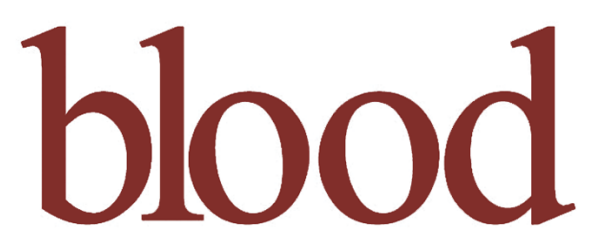

2004 103: 2079-2087

Prepublished online Nov 20, 2003;

doi:10.1182/blood-2003-06-1770

\title{
Impaired bone marrow homing of cytokine-activated CD34+cells in the NOD/SCID model
}

Forhad Ahmed, Stuart J. Ings, Arnold R. Pizzey, Michael P. Blundell, Adrian J. Thrasher, Hong T. Ye, Anne Fahey, David C. Linch and Kwee L. Yong

Updated information and services can be found at:

http://bloodjournal.hematologylibrary.org/cgi/content/full/103/6/2079

Articles on similar topics may be found in the following Blood collections:

Apoptosis (747 articles)

Cell Cycle (231 articles)

Cell Adhesion and Motility (790 articles)

Hematopoiesis and Stem Cells (2401 articles)

Information about reproducing this article in parts or in its entirety may be found online at:

http://bloodjournal.hematologylibrary.org/misc/rights.dtl\#repub_requests

Information about ordering reprints may be found online at:

http://bloodjournal.hematologylibrary.org/misc/rights.dtl\#reprints

Information about subscriptions and ASH membership may be found online at:

http://bloodjournal.hematologylibrary.org/subscriptions/index.dtl

Blood (print ISSN 0006-4971, online ISSN 1528-0020), is published

semimonthly by the American Society of Hematology, 1900 M St, NW, Suite 200, Washington DC 20036.

Copyright 2007 by The American Society of Hematology; all rights reserved.

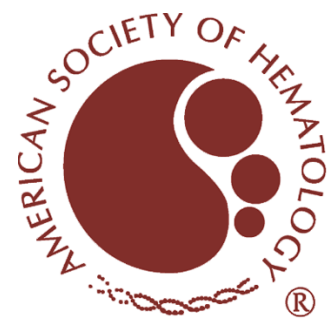




\section{Impaired bone marrow homing of cytokine-activated $\mathrm{CD} 34^{+}$cells in the NOD/SCID model}

Forhad Ahmed, Stuart J. Ings, Arnold R. Pizzey, Michael P. Blundell, Adrian J. Thrasher, Hong T. Ye, Anne Fahey,

David C. Linch, and Kwee L. Yong

The reduced engraftment potential of hematopoietic stem/progenitor cells (HSPCs) after exposure to cytokines may be related to the impaired homing ability of actively cycling cells. We tested this hypothesis by quantifying the short-term homing of human adult CD $34^{+}$cells in nonobese diabetic/severe combined immunodeficient (NOD/SCID) animals. We show that the loss of engraftment ability of cytokine-activated CD34+ cells is associated with a reduction in homing of colony-forming cells (CFCs) to bone mar- row (BM) at 24 hours after transplantation (from median $2.8 \%$ [range, $1.9 \%-6.1 \%$ ] to $0.3 \%[0.0 \%-0.7 \%] ; n=3 ; P<.01)$, coincident with an increase in CFC accumulation in the lungs $(P<.01)$. Impaired BM homing of cytokine-activated cells was not restored by using sorted cells in $\mathrm{G}_{0} \mathrm{G}_{1}$ or by inducing cell cycle arrest at the $G_{1} / S$ border. Blocking Fas ligation in vivo did not increase the BM homing of cultured cells. Finally, we tested cytokine combinations or culture conditions previously reported to restore the engraftment of cul- tured cells but did not find that any of these was able to reverse the changes in homing behavior of cytokine-exposed cells. We suggest that these changes in homing and, as a consequence, engraftment result from the increased migratory capacity of infused activated cells, leading to the loss of selectivity of the homing process. (Blood. 2004;103:2079-2087)

๑) 2004 by The American Society of Hematology

\section{Introduction}

Hematopoietic stem/progenitor cell (HSPC) transplantation is now a recognized therapeutic strategy for the treatment of malignant and nonmalignant disorders. Much effort has focused on ex vivo manipulation of these cells, not only to expand small HSPC collections such as cord blood but also for genetic modification either to replace defective genes or to express therapeutic genes of interest. Cell expansion and gene transduction strategies, however, involve cytokine stimulation, which may compromise engraftment potential. Exposure of stem cells to growth factors in vitro reduces the in vivo repopulating ability of these cells, as demonstrated in murine and xenogeneic systems ${ }^{1,2}$ and as evidenced in studies on retrovirally transduced cells. ${ }^{3,4}$ Results from such studies suggest that when human HSPCs are stimulated to proliferate in vitro, there is a loss of engraftment ability as cells progress into active phases of the cell cycle. ${ }^{5-8} \mathrm{~A}$ study using highly purified murine stem cells found this engraftment defect to be reversible and to oscillate as cells undergo synchronous cell cycle passage. ${ }^{9}$ In murine Lin $^{-}$ bone marrow (BM) cells cultured in Flt ligand (FL), stem cell factor (SCF), and interleukin-11 (IL-11), repopulating capability decreased dramatically just before cell division but recovered 24 hours later, at which time the repopulating cells were recovered in the divided fraction. ${ }^{10}$ Such observations have led to the speculation that actively cycling stem/progenitor cells are unable to "home" to the hematopoietic tissue. This homing defect is especially pronounced for cells in the $S / G_{2} / M$ phase. Support for this hypothesis derives from murine studies in which seeding of
HSPCs/colony-forming cell (CFCs) to the BM/spleen was found to decrease after ex vivo cytokine exposure. ${ }^{1,11}$ There has not yet been a systematic study of the effects of cytokine stimulation on the homing abilities of adult human HSPCs.

"Homing" refers to the selective ability of circulating HSPCs to localize within the $\mathrm{BM}$, and it involves a complex series of adhesive and migratory processes that are still not fully understood. Our previous studies in this area have focused on the early critical step of transendothelial migration, whereby HSPCs egress from the circulation into hematopoietic tissue. We have shown that though $\mathrm{CD} 4^{+}$cells adhere readily to the endothelial surface, they do not undergo transmigration unless activated by cytokines that induce cell division. ${ }^{12}$ Migratory capacity is selectively greater for cells that are in the $G_{0} G_{1}$ phase of the cell cycle, ${ }^{13}$ a finding recently confirmed by others. ${ }^{14}$ Although these observations provide a possible basis for the cell cycle dependency of engraftment, we have yet to obtain direct confirmation that the defective engraftment of cytokine-cultured cells occurs as a result of reduced homing ability or that either is directly related to cell cycle progression.

Recently, much interest has focused on modifying culture conditions so as to restore the engraftment capability of preactivated cells. IL-3 has been implicated in the loss of long-term reconstituting activity of cultured $\mathrm{HSPCs},{ }^{15}$ whereas cytokines that selectively stimulate primitive HSPCs, such as thrombopoietin (TPO), SCF, and FL, have been reported to preserve long-term
From the Departments of Haematology and Histopathology, Royal Free and University College Medical School, London; the Molecular Immunology Unit, Institute of Child Health, London, United Kingdom; and the Department of Pathology, Guangxi Medical University, China.

Submitted June 2, 2003; accepted November 12, 2003. Prepublished online as Blood First Edition Paper, November 20, 2003; DOI 10.1182/blood-2003-061770 .

Supported by the Medical Research Council, UK (F.A.).
Reprints: Kwee L. Yong, Department of Haematology, Royal Free and University College Medical School, 98 Chenies Mews, London, WC1E 6HX, United Kingdom; e-mail: kwee.yong@ucl.ac.uk.

The publication costs of this article were defrayed in part by page charge payment. Therefore, and solely to indicate this fact, this article is hereby marked "advertisement" in accordance with 18 U.S.C. section 1734.

(C) 2004 by The American Society of Hematology 
repopulating cells. ${ }^{16,17}$ It is difficult to make direct comparisons among such studies, which vary in terms of the cell source, the use of serum-free media, and the in vivo model (murine, nonobese diabetic/severe combined immunodeficient [NOD/SCID], or SCID-hu bone). In addition, not all take into account the degree of cell expansion after culture. Nevertheless, in HSPCs stimulated to divide after exposure to TPO/SCF/FL in vitro, NOD/SCIDrepopulating activity is maintained and is demonstrated by cells in the postmitotic compartment. ${ }^{18,19}$ If actively cycling HSPCs have an engraftment defect, then modulating cell cycle progression to induce quiescence at the time of infusion might restore the repopulating potential. Exposure to transforming growth factor- $\beta$ (TGF- $\beta$ ) increased the proportion of HSPCs in the $\mathrm{G}_{0} \mathrm{G}_{1}$ phase of the cell cycle but did not aid engraftment in either a murine model or a xenogeneic model. ${ }^{5,20}$ In a recent study, preactivated primate $\mathrm{CD} 34^{+}$cells were "rested" for 2 days in SCF and retronectin, resulting in an increase in the proportion of cells in $\mathrm{G}_{0} \mathrm{G}_{1}$ and in superior engraftment compared with control "nonrested" cells. ${ }^{21}$ Stromal cell-derived factor-1 (SDF-1) has recently been reported to enhance survival while inhibiting the cycling of HSPCs. ${ }^{22,23}$ Incubation of proliferating cord blood $\mathrm{CD}_{3} 4^{+}$cells with SDF and TPO produced an increase in competitive repopulating unit (CRU) frequency, though without any changes in the cell cycle profile of the cells. ${ }^{23}$ Intriguingly, there is now evidence that the cell cycle constraints on engraftment may not apply to HSPCs from early ontogeny. Fetal liver $\mathrm{CD} 34^{+}$cells, whether in $\mathrm{G}_{0}, \mathrm{G}_{1}$, or $\mathrm{S} / \mathrm{G}_{2} / \mathrm{M}$, are able to engraft immunodeficient animals. ${ }^{24}$ Although there may be ontogeny-related differences in the homing and engraftment behavior of HSPCs from different sources, this finding raises the possibility that the engraftment defect of cultured cells is the result of ex vivo cytokine activation and is not directly related to cell cycling.

The present study was designed to test the hypothesis that the reduced engraftment of cytokine-stimulated CD $34^{+}$cells is directly related to an alteration in short-term, organ-specific homing. We also sought to determine whether alterations in the homing and engraftment of cytokine-stimulated $\mathrm{CD} 34^{+}$cells are cell cycle dependent. We quantified short-term homing of human CFCs to different organs in NOD/SCID animals in parallel with engraftment studies carried out on the same cells. We investigated the cell cycle dependence of the homing and engraftment process by using sorted cells in $\mathrm{G}_{0} \mathrm{G}_{1}$ and $\mathrm{S} / \mathrm{G}_{2} / \mathrm{M}$ phases of the cell cycle and also by inducing cell cycle arrest at the $\mathrm{G}_{1} / \mathrm{S}$ border, followed by synchronized S-phase progression. Finally, we tested several ex vivo maneuvers that have been reported to restore the engraftment of preactivated cells to investigate whether such strategies were able to modulate the homing behavior of adult $\mathrm{CD} 34^{+}$cells.

\section{Materials and methods}

\section{Materials}

Cytokines. Recombinant human (rh) SCF, FL, IL-6, TPO, and SDF-1 were obtained from PeproTech (London, United Kingdom). IL-3 was from Sandoz (Camberley, United Kingdom) and granulocyte macrophage-colonystimulating factor (GM-CSF) was from Hoechst (Marburg, Germany).

Monoclonal antibodies. Fluorescein isothiocyanate (FITC), peridinin chlorophyll protein (PerCP), and phycoerythrin (PE)-conjugated monoclonal antibodies (mAbs) (anti-CD34, -CD38, -CD45, -CD3, -CD2, -CD19) were obtained from Becton Dickinson (Oxford, United Kingdom). AntiCXCR-4PE and anti-Fas-PE were obtained from PharMingen (San Diego, CA). Anti-CD13 and -CD38 were from DAKO (Ely, United Kingdom).

Reagents. Iscove modified Dulbecco medium (IMDM), phosphatebuffered saline (PBS), and Hanks balanced salt solution (HBSS) were obtained from Life Technologies (Paisley, United Kingdom), and fetal calf serum (FCS) was from PAA Laboratory GmbH (Linz, Austria).

\section{$\mathrm{CD}^{+}{ }^{+}$cell isolation}

Mobilized peripheral blood (MPB) was obtained from patients at University College London Hospitals (UCLH) using cyclophosphamide/G-CSF in accordance with local ethical guidelines. $\mathrm{CD} 34^{+}$cells were isolated using a large-scale CliniMACs system ${ }^{25}$ (Miltenyi Biotec GmbH, Bergisch Gladbach, Germany). CD $34^{+}$cell preparations, as evaluated by immunofluorescence, had an average purity of $93 \% \pm 3 \%$. Freshly isolated versus cryopreserved cells were compared for CFC output, in vivo homing, and engraftment, and no significant difference was found.

\section{Cell culture}

Cells were cultured in X-VIVO 10 (BioWhittaker, Walkersville, MD) and $1 \%$ human serum albumin (HSA) (Immuno Ltd, Kent, United Kingdom) supplemented with SCF, FL (100 ng/mL), IL-3, and IL-6 (20 ng/mL). In some experiments cells were cultured with SCF, FL (100 ng/mL), and TPO $(20 \mathrm{ng} / \mathrm{mL})$ or SCF, TPO $(50 \mathrm{ng} / \mathrm{mL})$, and SDF-1 (100 ng/mL). In appropriate experiments cells were also cultured on RetroNectin (Takara Shuzo, Shiga, Japan). Percentage of $\mathrm{CD} 4^{+}$cells up to 96 hours in culture was $87 \% \pm 4 \%$. The viability of cultured cells was greater than $95 \%$, as judged by trypan blue (TB) exclusion.

\section{Cell synchronization using aphidicolin}

$\mathrm{CD}_{4} 4^{+}$cells were stimulated with SCF, FL, and TPO at $100 \mathrm{ng} / \mathrm{mL}$ in X-VIVO 10/1\% HSA. After 16 hours, aphidicolin $(2 \mu \mathrm{g} / \mathrm{mL}$; Sigma, Poole, United Kingdom) was added, and incubation was continued for another 24 hours, as described previously. ${ }^{26} \mathrm{At}$ the end of this incubation (40 hours altogether), cells were washed and replated in X-VIVO 10/1\% HSA with cytokines to allow S-phase progression. Cells were harvested at 3 and 6 hours thereafter to assess their position in the cell cycle and their homing ability.

\section{Fas/CD95 blocking experiment}

CD34 ${ }^{+}$cells were stimulated with SCF, FL (100 ng/mL), and IL-3, IL-6 (20 $\mathrm{ng} / \mathrm{mL}$ ) in X-VIVO $10 / 1 \%$ HSA. In experiments using a blocking mAb, 48-hour-cultured cells were preincubated for 30 minutes on ice with anti-Fas mAb (clone ZB4; mouse IgG1; MBL International, Watertown, MA). Cells were not washed but were injected in the presence of antibody. In a second set of experiments, human recombinant soluble Fas ligand (sFasL; Alexis, Nottingham, United Kingdom) was included in the culture medium (48-72 hours). Before transplantation, cells were washed and resuspended in fresh medium with sFasL for injection.

\section{Cell cycle fractionation with Hoechst 33342}

Cultured $\mathrm{CD} 4^{+}$cells (48 hours) were resuspended at $5 \times 10^{6} / \mathrm{mL}$ in 10 $\mu \mathrm{M}$ solution of Hoechst (Hst) 33342 (Molecular Probes, Eugene, OR) in Hst buffer (HBSS, $20 \mathrm{mM}$ HEPES [ $N$-2-hydroxyethylpiperazine- $N^{\prime}-2-$ ethanesulfonic acid], $1 \mathrm{~g} / \mathrm{L}$ glucose, $10 \% \mathrm{FCS}$ ). After incubation at $37^{\circ} \mathrm{C}$ for 45 minutes, cells were washed once (in chilled Hst buffer), resupended in Hst buffer, and sorted on a FACS vantage (Beckman Coulter, High Wycombe, United Kingdom) equipped with a multiline ultraviolet laser (351-364 nm) providing excitation for Hst. The Hst signal was detected with a $424 \pm 22 \mathrm{~nm}$ band-pass filter. Sorting windows were constructed to sort $\mathrm{G}_{0} / \mathrm{G}_{1}$ from $\mathrm{S} / \mathrm{G}_{2} / \mathrm{M}$ populations. Cells were kept on ice during sorting to minimize dye leaking and were protected from light. No effect of Hst staining on colony formation was detected (data not shown). The purity of sorted $\mathrm{G}_{0} / \mathrm{G}_{1}$ cells exceeded $98 \%$, and that of $\mathrm{S} / \mathrm{G}_{2} / \mathrm{M}$ cells exceeded $83 \%$.

\section{Labeling human MPB CD34+ cells with PKH26}

Fresh or cultured MPB $\mathrm{CD} 34^{+}$cells were labeled with PKH26 dye according to manufacturer's (Sigma) instructions, with some modifications. Briefly, cells were resuspended in diluent $\mathrm{C}$ at a concentration of 20$40 \times 10^{6} / \mathrm{mL}$, combined with an equal volume of PKH26 dye freshly prepared at $10 \mu \mathrm{M}$ in diluent $\mathrm{C}$, and incubated at room temperature for 4 
Table 1. Effect of cytokine stimulation on the engraftment of CD34 ${ }^{+}$ cells in NOD/SCID mice: 2 to 5 days

\begin{tabular}{ccccccc}
\hline \multirow{2}{*}{ Experiment } & \multicolumn{2}{c}{ Cells/mouse, $\mathbf{1 0}^{6}$} & & \multicolumn{2}{c}{ CD45+ cells in mouse BM, \% } \\
\cline { 2 - 3 } \cline { 6 - 7 } \cline { 6 - 7 } & Fresh & Postculture & & Fresh & Postculture \\
\hline 1 & 0.5 & 0.7 & & $2.0,2.3$ & $0.0,1.3$ \\
\hline 1 & 0.5 & 2.6 & & 4.6 & 2.7 \\
2 & 1.0 & 1.3 & & $2.1,10.5$ & $0.1,0.1$ \\
Median (range) & NA & NA & & $4.6(2.0-78.4)$ & $0.7(0.0-22.7)^{*}$ \\
Animals engrafted & NA & NA & & 7 of 7 & 3 of 7 \\
\hline
\end{tabular}

Freshly isolated $\mathrm{CD} 34^{+}$cells $\left(0.5\right.$ or $1.0 \times 10^{6}$ cells/animal) or the expanded equivalent number of cultured cells were infused into sublethally irradiated NOD/ SCID mice. Cultured cells were stimulated with SCF $(100 \mathrm{ng} / \mathrm{mL}), \mathrm{FL}(100 \mathrm{ng} / \mathrm{mL})$, IL-3 $(20 \mathrm{ng} / \mathrm{mL})$, and IL- $620 \mathrm{ng} / \mathrm{mL})$ in X-VIVO 10 with $1 \%$ FCS for 2 to 5 days. For al experiments, engraftment was assessed 6 weeks after transplantation using immunophenotype analysis of BM cells, as detailed in "Materials and methods." An animal was considered to have experienced successful engraftment if $\mathrm{CD}_{4} 5^{+}$cells comprised $1 \%$ or more of BM cells. Data are given for each animal and as the median and range of each group, as indicated.

NA indicates not applicable.

${ }^{\star} P<.05$ compared with fresh cells; Mann-Whitney $U$ test.

minutes with periodic gentle mixing. An equal volume of FCS was added for 1 minute, and labeled cells were then washed 3 times in HBSS $/ 2 \%$ FCS Aliquots of cells before and after PKH26 staining were assayed for CFCs and generated comparable numbers of total colonies (data not shown). The remaining cells were then injected intravenously into sublethally irradiated or nonirradiated NOD/SCID mice (10 million cells per mouse).

\section{Mice and transplantation of human MPB CD $34^{+}$cells}

NOD/LtSz-PrKdc scid (NOD/SCID) mice were housed under positive pressure in a ventirack obtained from Biozone (Kent, United Kingdom). Eightto 10 -week-old mice were sublethally irradiated ( $325 \mathrm{cGy}$ from a cesium Cs 137 source) and immediately underwent transplantation with fresh or cytokine-cultured human $\mathrm{CD} 34^{+}$cells $\left(0.5-2 \times 10^{6} /\right.$ animal $)$ by lateral tail vein injection. Mice were killed by $\mathrm{CO}_{2}$ inhalation at selected intervals after transplantation

\section{Analysis of murine tissues for human progenitor cell homing}

BM cell suspensions were prepared from 2 femurs and 1 tibia and from spleens, lungs, and livers. Red blood cells (RBCs) were lysed in $155 \mathrm{mM}$ $\mathrm{NH}_{4} \mathrm{Cl}, 20 \mathrm{mM} \mathrm{NaHCO} 3$, and $1 \mathrm{mM}$ EDTA (ethylenediaminetetraacetic acid; BDH, Poole, United Kingdom). Cells were washed once in 5\% FCS/HBSS and were set up in clonogenic assays in methylcellulose (Methocult [H4230]; Stem Cell Technologies, Vancouver, BC, Canada) with $20 \%$ IMDM supplemented with GM-CSF $25 \mathrm{ng} / \mathrm{mL}$, SCF $10 \mathrm{ng} / \mathrm{mL}$, and IL-3 $30 \mathrm{ng} / \mathrm{mL}$. These conditions are selective for human colonies because no colony growth was seen using BM from control saline-injected animals. Purified CD34 ${ }^{+}$cells $\left(5.0 \times 10^{2} / \mathrm{mL}\right)$ or harvested BM mononuclear cells (BMMNCs; $2-4 \times 10^{5} / \mathrm{mL}$ ) were plated in quadruplicate. Total human GM-CFC colonies per animal were calculated on the basis of the assumption that 1 tibia and 2 femurs represent $12 \%$ of total $\mathrm{BM}^{27}$ and were expressed as a percentage of the number of GM-CFCs infused. To quantify the level of homing in other tissues, GM-CFCs were counted and expressed per $10^{6}$ cells.

\section{Analysis of human cell engraftment}

Six weeks after infusion, mice were killed, and single-cell suspensions were prepared from the BM of 2 femurs and 1 tibia. After RBC lysis, BMMNCs $\left(10^{6}\right.$ cells/tube) were incubated with $100 \mu \mathrm{L}$ mouse serum (Sigma) in PBS/1\% bovine serum albumin (BSA) for 15 minutes on ice. After washing, cells were stained at $4^{\circ} \mathrm{C}$ with antihuman CD45-PerCP, CD34FITC, CD38-FITC, CD19-PE, CD13-FITC, CD3-FITC, and CD2-PE in appropriate combinations in $100 \mu \mathrm{L}$ staining buffer (PBS/1\% BSA/0.1\% sodium azide). A sample from each mouse was also stained with isotypematched control antibodies. Cells were washed twice and fixed in $1 \%$ paraformaldehyde. Samples were analyzed on the Epics-Elite flow cytometer (Beckman-Coulter, High Wycombe, United Kingdom), and at least 50000 events were acquired and analyzed using Elite Workstation Analysis software version 4.5. An animal was considered to have achieved successful engraftment if the $\mathrm{BM}$ contained more than $1 \% \mathrm{CD} 45^{+}$cells.

\section{Cell cycle analysis}

$\mathrm{CD} 34^{+}$cells were stained with propidium iodide (PI) and were analyzed as described previously. ${ }^{12}$

\section{Statistical analysis}

Data are expressed as median and range of multiple measurements. Data are presented to 1 decimal point, except for flow cytometric measurements, which are rounded up to 2 significant figures. Determination of statistical significance between groups was carried out using the nonparametric Mann-Whitney $U$ test, and $P$ less than .05 was considered significant. Unless indicated, values are nonsignificant.

\section{Results}

\section{Cytokine activation reduces engraftment of MPB CD34 ${ }^{+}$cells in NOD/SCID animals}

We studied the engraftment of freshly isolated and cytokineactivated MPB CD34 ${ }^{+}$cells in NOD/SCID animals by fluorescenceactivated cell sorter (FACS) analysis of murine BM performed at 4 to 6 weeks after transplantation. Cytokine exposure (for more than 48 hours) led to an increase in cell number (130\%-520\% of initial). Hence, to avoid any dilutional effect on stem cells initially present in the graft, the numbers of cytokine-exposed CD34 ${ }^{+}$cells infused represented the expanded equivalent of fresh cells. Table 1 summarizes the results of the first set of experiments performed in this way. Animals that received cytokine-activated cells showed lower rates of engraftment ( 3 of 7 animals engrafted), whereas all animals receiving fresh cells engrafted (median, 4.6\%; range, $2.0 \%-78.4 \% \mathrm{CD}^{2} 5^{+}$cells in murine $\mathrm{BM}$ ). We also performed a second series of experiments in which equal numbers of fresh or cultured cells were infused (Table 2). Although the engraftment levels were generally lower, cultured cells again demonstrated a marked engraftment defect, such that no animal receiving cultured cells engrafted. Assessment of engraftment by FACS analysis was confirmed by colony assays on cells recovered from murine BM using human-specific cytokines (GM-CSF, SCF, and IL-3) (Figure

Table 2. Effect of cytokine stimulation on the engraftment of CD34 ${ }^{+}$ cells in NOD/SCID mice: 48 hours

\begin{tabular}{cccc}
\hline \multirow{2}{*}{ Experiment } & Cells/mouse, 106 & \multicolumn{2}{c}{ CD45 cells in mouse BM, \% } \\
\cline { 3 - 4 } & 0.5 & Fresh & Postculture \\
\hline 1 & 1.0 & $1.4,1.2$ & 0.1 \\
1 & 1.0 & $5.8,16.2$ & $0.1,0.0$ \\
2 & NA & $1.9,1.3$ & $0.5,0.1$ \\
Median (range) & NA & $1.7(1.2-16.0)$ & $0.1(0.0-0.5)^{\star}$ \\
Animals engrafted & 6 of 6 & 0 of 5 \\
\hline
\end{tabular}

Freshly isolated $\mathrm{CD} 34^{+}$cells $\left(0.5\right.$ or $1.0 \times 10^{6}$ cells/animal) or the equal number of cultured cells were infused into sublethally irradiated NOD/SCID mice. Cultured cells were stimulated with SCF $(100 \mathrm{ng} / \mathrm{mL}), \mathrm{FL}(100 \mathrm{ng} / \mathrm{mL}), \mathrm{IL}-3(20 \mathrm{ng} / \mathrm{mL})$, and IL-6 $(20 \mathrm{ng} / \mathrm{mL})$ in X-VIVO 10 with $1 \%$ FCS for 48 hours. For all experiments, engraftment was assessed 6 weeks after transplantation using immunophenotype analysis of BM cells, as detailed in "Materials and methods." An animal was considered to have experienced successful engraftment if $\mathrm{CD}_{4} 5^{+}$cells comprised $1 \%$ or more of BM cells. Data are given for each animal and as the median and range of each group, as indicated.

NA indicates not applicable.

${ }^{\star} P<.01$ compared with fresh cells; Mann-Whitney $U$ test. 
1A). Multilineage engraftment was demonstrated in animals that engrafted with either fresh or cytokine-activated cells, though the skewing to B-lineage engraftment seen using fresh $\mathrm{CD} 34^{+}$cells was not evident in animals that underwent transplantation with cytokine-activated cells (Figure 1B).

\section{Cytokine activation impairs short-term homing of $\mathrm{CD} 34^{+}$cells to BM in NOD/SCID animals}

Initial experiments were performed to assess the localization of freshly isolated $\mathrm{CD}_{3} 4^{+}$cells in various organs at 1 and 24 hours after transplantation. As seen in Figure 2A, the homing of CFCs to $\mathrm{BM}$ and spleen was evident at 1 hour after infusion, but the numbers of CFCs increased substantially at 24 hours. In contrast, although CFCs accumulated in the lungs at 1 hour, numbers were reduced at 24 hours, suggesting that this represented transient accumulation rather than active homing. To investigate the effect of cytokine exposure, $\mathrm{CD} 34^{+}$cells were incubated with FL, SCF, IL-3, and IL-6 for 2 to 5 days, and the expanded equivalent ( 2 or $5 \times 10^{6}$ ) of $\mathrm{CD}^{4} 4^{+}$cells was infused per animal. Cytokine stimulation resulted in marked reduction in the homing of CFCs to the $\mathrm{BM}$ when assessed at 1 and 24 hours (medians, 2.0\% [range, $0.5 \%-2.4 \%$ ] and $2.8 \%$ [range, $1.9 \%-6.1 \%$ ] for fresh GM-CFCs vs $0.1 \%[0.0 \%-0.2 \%]$ and $0.3 \%[0.0 \%-0.7 \%]$ for cultured cells at 1 and 24 hours, respectively; $\mathrm{n}=3)(P<.01$ for both time points $)$ (Figure 2A). In contrast, cytokine-stimulated CFCs showed significantly increased localization to lung tissue at 1 hour $(P<.05)$ and 24 hours $(P<.01)$ after infusion. The BM homing defect was evident after 2 days of cytokine exposure and remained unaltered up to 5 days (Figure 2B). Cytokine-activated $\mathrm{CD}^{+} 4^{+}$cells also showed significant reduction in homing to the spleen (Figure 2C). A detailed time course of cytokine exposure showed that homing of CFCs to the BM was significantly impaired by 24 hours after cytokine stimulation and had already begun to decrease at 4 hours (Figure 2D). In further experiments, we used cells stimulated for 48 hours because these cells had not expanded significantly and, therefore, they avoided any confounding effect from the infusion of large numbers of cells.
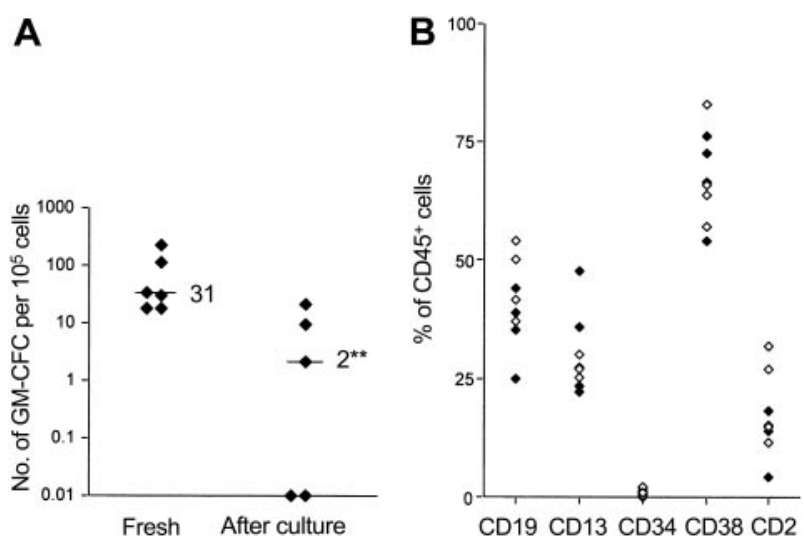

Figure 1. Effect of cytokine stimulation on the engraftment of CD34+ cells in NOD/SCID mice. (A) Engraftment was assessed at 4 to 6 weeks after transplantation in mice that received freshly isolated CD34 ${ }^{+}$cells or cultured cells $\left(0.5\right.$ or $1.0 \times 10^{6}$ cells/animal). Bone marrow cells were assayed for human colony formation (as detailed in "Materials and methods"). Data are given for each animal in 2 independent experiments, and the median for each group is indicated. (B) Lineage-specific engraftment of fresh $(\diamond)$ and cultured cells $(\diamond)$ was assessed by flow cytometry. The percentage of huCD $45^{+}$cells that also expressed human lymphoid, myeloid, and progenitor surface markers is shown. Data are given for each animal from 2 independent experiments. ${ }^{* *} P<.01$ compared with fresh cells; Mann-Whitney $U$ test.

\section{Assessment of short-term homing of transplanted CD34 ${ }^{+}$cells by flow cytometric assay}

It is possible that $\mathrm{CFC}$ recovery of expanded human $\mathrm{CD} 34^{+}$cells is adversely affected by conditions in the irradiated murine BM. Hence, we sought to confirm our results on clonogenic cells by determining the actual numbers of cells that had homed to the BM at 24 hours. To track intravenously transplanted human MPB $\mathrm{CD} 4^{+}$cells, we used a well-established cell-labeling procedure with the fluorescent dye PKH26. Using the staining method described in "Materials and methods," $99 \%$ of MPB CD34+ cells could be brightly stained, yielding a fluorescence intensity at least 1 log higher than that of unlabeled control cells (data not shown). PKH26 staining did not have any deleterious effect on CFC growth, as assessed by methylcellulose colony assay in vitro. PKH26labeled cells generated comparable numbers of total colonies as unstained cells (data not shown), indicating that PKH26 does not alter the functional activity of hematopoietic progenitors and is suitable to track their homing in vivo.

To evaluate the effect of cytokine exposure on homing in vivo, $\mathrm{BM}$ from mice transplanted with unlabeled and $\mathrm{PKH} 26-$ labeled cells (fresh and postculture) was collected at 24 hours after transplantation and were analyzed for the presence of PKH26labeled cells by flow cytometry. Table 3 shows the number of labeled cells detected in irradiated (experiment 2) and nonirradiated (experiment 1) mice per million BM cells analyzed at 24 hours by flow cytometry. It is clear that the short-term (24-hour) homing of $\mathrm{CD}_{3} 4^{+}$cells was consistently reduced after 48 hours of culture in cytokines $(P<.01)$. There was a mean 5 -fold reduction in homing of the cytokine-treated (48-hour) cells when compared with noncultured fresh $\mathrm{CD} 34^{+}$cells. Results from 2 independent experiments are presented in Table 3. As reported previously, ${ }^{28}$ homing to nonirradiated $\mathrm{BM}$ was 2 to 4 times higher than to irradiated BM, and this difference was observed for fresh and cultured cells (Table 3 ).

Immunohistochemical staining confirmed the presence of CD45 ${ }^{+}$ cells in murine BM sections at 24 hours after transplantation (data not shown). When compared with animals that had received fresh CD34 ${ }^{+}$cells, animals that had received cytokine-activated cells showed reduced numbers of $\mathrm{CD}_{4} 5^{+}$cells in $\mathrm{BM}$ sections but increased numbers in lung sections (data not shown).

\section{Influence of cell cycle phase on short-term BM homing of cytokine-activated cells}

These results suggest that reduced engraftment after cytokine exposure is predicted by alterations in the homing behavior of these cells in vivo. Cytokine stimulation increases the proportion of actively cycling cells (from $3 \% \pm 1 \%$ to $28 \% \pm 3 \%$ in $\mathrm{S} / \mathrm{G}_{2} / \mathrm{M}$ after 48 hours). The time course of the observed changes in BM homing (Figure 2D) closely follows the kinetics of cells entering the active phase of the cell cycle (percentages of cells in $\mathrm{G}_{0} \mathrm{G}_{1}$ at 0 , 4, 24, and 48 hours of culture were $96 \pm 1,98,81 \pm 9$, and $72 \pm 2$, respectively; $n=3$ ), suggesting that cytokine-induced changes in $\mathrm{BM}$ homing may relate to position in the cell cycle. To test this hypothesis, sorted $G_{0} G_{1}$ and $S / G_{2} / M$ fractions (Figure $3 A$ ) of cultured $\mathrm{CD}_{3} 4^{+}$cells were tested for $\mathrm{CFC}$ homing to the $\mathrm{BM}$ and spleen. CFCs from the $\mathrm{G}_{0} \mathrm{G}_{1}$ fraction showed a small increase in BM homing compared with their counterparts in $S / G_{2} / M$; however, this did not reach significance and remained significantly lower than the homing of unstimulated cells (Figure 3B). Parallel studies on the engraftment of these cell fractions confirmed that sorted $\mathrm{G}_{0} \mathrm{G}_{1}$ cells had no engraftment advantage compared with unsorted 
Figure 2. Homing of freshly isolated and cytokine stimulated CD34 $^{+}$cells. (A) Cell suspensions from the BM, spleen, and lungs of transplanted NOD/SCID mice recovered 1 hour and 24 hours after transplantation were assayed for colony formation using humanspecific cytokines. Numbers of CFCs in lungs and spleen were corrected for the cell expansion after cytokine culture. Medians interquartiles, and ranges of 4 to 7 animals pooled from 3 experiments. (B) Time course of changes in BM homing after cytokine activation. CD34 ${ }^{+}$cells exposed to cytokines for 2,4 , or 5 days were infused into sublethally irradiated animals, and homing to BM was assessed 24 hours after infusion. Homing of fresh cells is shown for comparison. Data are from 4 independent experiments; each data point represents 1 animal, and the mean values are indicated. (C) Homing of freshly isolated CD34+ cells or cultured cells after 24 and 48 hours of culture to the spleen at 24 hours after transplantation. (D) $\mathrm{CD}_{3}{ }^{+}$cells were cultured for $1,4,24$, or 48 hours, and homing of infused cells to BM was assessed at 24 hours after transplantation; $\mathrm{n}=2$ experiments, data given for each animal $\left({ }^{\star} P<.05 ;{ }^{* \star} P<.01\right.$; ${ }^{* * *} P<.001$ compared with fresh cells; Mann-Whitney $U$ test).
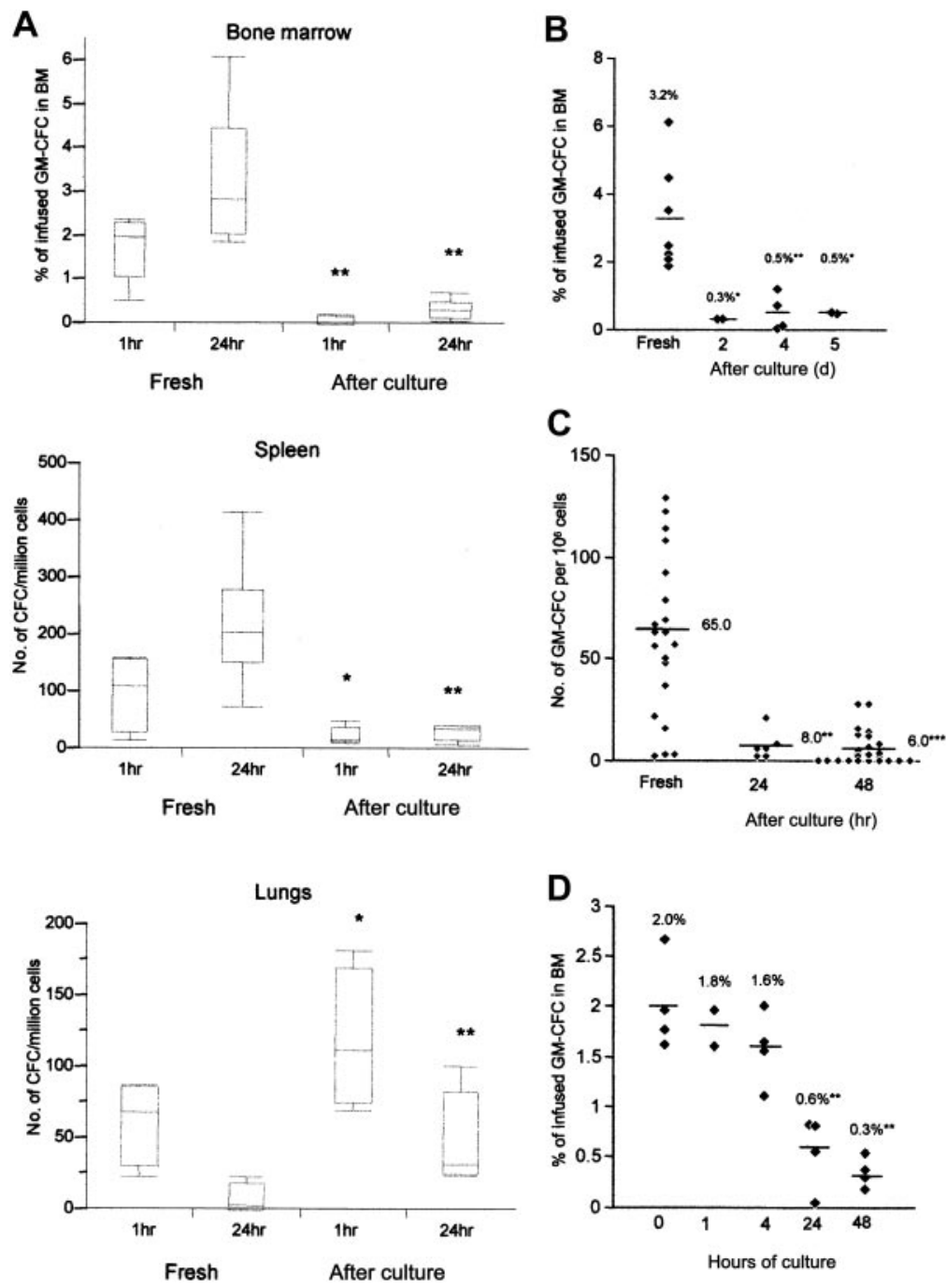

cells or with cells in the $S / G_{2} / M$ fraction $\left(\mathrm{G}_{0} \mathrm{G}_{1}\right.$ cells, $0.1 \% \mathrm{CD} 45^{+}$; unsorted cells, $0.2 \% \mathrm{CD} 45^{+} ; \mathrm{S} / \mathrm{G}_{2} / \mathrm{M}$ cells, $\left.0.1 \% \mathrm{CD} 45^{+}\right)$.

We cannot exclude the possibility that cell sorting might have an effect on homing capabilities of $\mathrm{CD} 34^{+}$cells or that sorted $\mathrm{G}_{0} \mathrm{G}_{1}$ cells did not display higher levels of homing because the critical cells important for homing and engraftment lay in the $S / G_{2} / M$ fraction. To address these issues, we used aphidicolin to induce cell cycle arrest at the $\mathrm{G}_{1} / \mathrm{S}$ border before the first cell division. ${ }^{26}$

Table 3. Number of PKH26-labeled cells detected in NOD/SCID BM 24 hours after transplantation

No. $\mathrm{PKH}^{2} 6^{+}$events/million BM cells

\begin{tabular}{llcc}
\cline { 2 - 4 } CD34+ cells & \multicolumn{1}{c}{ Staining } & Experiment 1 & Experiment 2 \\
\hline Fresh & Control & 4 & 2 \\
Postculture & PKH26-labeled & 695,1136 & 391,292 \\
& Control & 1 & 2 \\
& PKH26-labeled & 201,204 & 68,48 \\
\hline
\end{tabular}

Freshly isolated $\mathrm{CD}_{3} 4^{+}$or cultured cells (unstained and PKH26-labeled) were infused into sublethally irradiated NOD/SCID mice. Cultured cells were stimulated with SCF $(100 \mathrm{ng} / \mathrm{mL}), \mathrm{FL}(100 \mathrm{ng} / \mathrm{mL}), \mathrm{IL}-3(20 \mathrm{ng} / \mathrm{mL})$, and IL-6 $(20 \mathrm{ng} / \mathrm{mL})$ in X-VIVO 10 with $1 \%$ HSA for 48 hours. For each experiment, homing was assessed 24 hours after transplantation by flow cytometric analysis of BM cells, as detailed in "Materials and methods." Data for the homing of cells has been presented here as number of positive events per million BM cells analyzed. Data are given for each animal from 2 independent experiments. Mice in experiment 1 were nonirradiated.
$\mathrm{CD}_{4}{ }^{+}$cells were stimulated with SCF, FL, and TPO, and aphidicolin was used to arrest cells at $\mathrm{G}_{1} / \mathrm{S}$ border, as detailed in "Materials and methods." At the end of the 40-hour culture, $95 \%$ of live cells treated with aphidicolin (Figure 4Aii) were in $\mathrm{G}_{0} \mathrm{G}_{1}$ compared with $65 \%$ of control cells incubated in cytokines alone (Figure 4Aiii). After release from the cell cycle block, cells moved into the $\mathrm{S}$ phase (at 3 hours, Figure 4Aiv) and then the $\mathrm{G}_{2} \mathrm{M}$ phase (6 hours, Figure 4Av) of the cell cycle in a synchronized manner. Treatment with aphidicolin did not alter the percentage of apoptotic cells. Cells were harvested at these time points of culture and were infused into conditioned animals. As seen in Figure 4B, these different cell populations displayed very similar levels of BM homing, with the exception of cells at 3 hours after the aphidicolin block (45\% in $\mathrm{S}$ phase), which achieved lower levels of homing. Importantly, cells arrested at the $\mathrm{G}_{1} / \mathrm{S}$ border displayed homing levels similar to those of control cultured cells that had progressed unchecked through the cell cycle. Thus, arresting cells at the $\mathrm{G}_{1} / \mathrm{S}$ border did not restore the homing ability of cultured cells.

\section{Role of Fas-ligand}

The above findings suggest that cell cycle progression could not explain the reduced BM homing behavior of cytokine-activated $\mathrm{CD}_{3} 4^{+}$cells. Among the surface receptors altered by the cytokine exposure of $\mathrm{CD}_{3} 4^{+}$cells is Fas. As seen in Figure 5A, Fas 
A
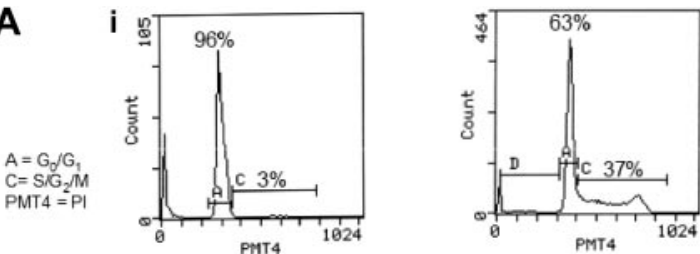

PMT2 = Hst

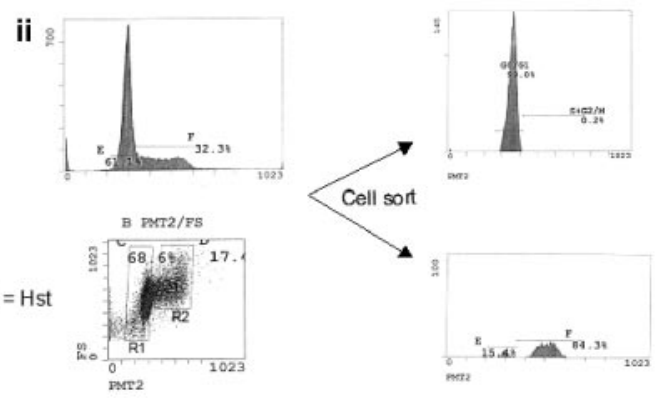

B

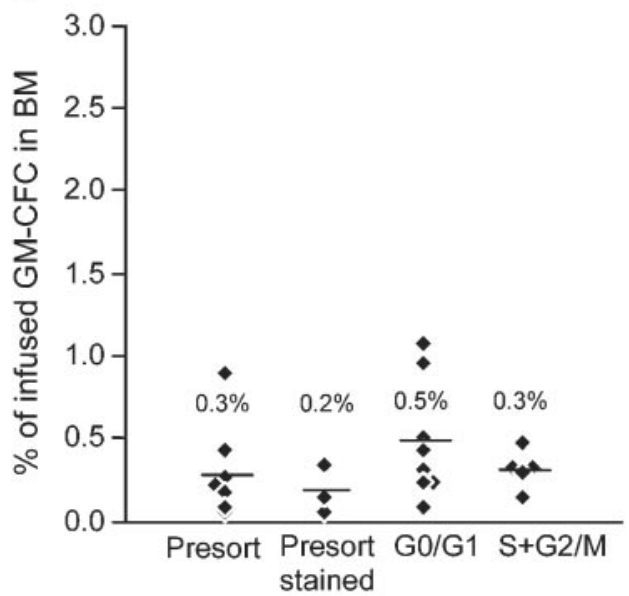

Figure 3. Cell cycle fractionation of cytokine-stimulated $\mathrm{CD}_{3} 4^{+}$cells and the effect on homing. (A) Cell cycle analysis of MPB CD34 ${ }^{+}$cells by PI (i) and fractionation using Hst and Py $Y$ staining (ii). Bars indicate gates for $G_{0} G_{1}(A)$ and $S / G_{2} M(C)$ subpopulations, and percentage of cells in each gate is given. (Ai) DNA histograms of MPB CD34 ${ }^{+}$cells immediately after isolation (left) and 48 hours after culture (right) by PI staining (Aii) Cultured $\mathrm{CD}_{3}{ }^{+}$cells were simultaneously stained with Hst and Py Y. The flow histogram shows gates indicating $G_{0} / G_{1}(R 1)$ and $S / G_{2} / M(R 2)$ populations of MPB CD34+ cells (left). Sort windows to collect $G_{0} / G_{1}$ and $S / G_{2} / M$ cells are indicated as regions $R 1$ and $R 2$, respectively. The purity of sorted $G_{0} / G_{1}$ cells (top right) exceeded $98 \%$ and of $S / G_{2} / M$ cells (bottom right) exceeded $83 \%$. Results from a representative experiment are shown. (B) Short-term BM homing of CD34+ cells in $G_{0} / G_{1}$ or $S / G_{2} / M$. Sorted $G_{0} / G_{1}$ and $S / G_{2} / M$ fractions of cultured $\mathrm{CD} 34^{+}$cells were infused $\left(0.5-2.0 \times 10^{6}\right.$ cells/animal) into sublethally irradiated NOD/SCID animals, and BM homing of progenitor cells was assessed as for Figure 2. Cultured cells that were unstained (presort) or stained (presort stained) served as controls. Data are from 4 independent experiments. Each data point represents 1 animal, and numbers and bars indicate the means.

expression on $\mathrm{CD}_{34}{ }^{+}$cells increased from $6 \% \pm 1 \%$ to $65 \% \pm 9 \%$ after 2 days of culture $(P<.01)$. In comparison, CXCR4 expression also increased with cell culture, an effect that did little to explain the decrease in homing. Ligation of surface Fas molecules with endogenous Fas-ligand in vivo may lead to the premature destruction of infused cells. We used 2 different approaches to attempt to block Fas engagement in vivo. First, we preincubated cytokinestimulated $\mathrm{CD} 34^{+}$cells with the blocking anti-Fas mAb, ZB4, before infusion. Alternatively, we also treated cytokine-stimulated $\mathrm{CD} 34^{+}$cells with $\mathrm{sFas}$, which has been suggested to have a protective role through competition against membrane-bound Fas-ligand. ${ }^{29}$ Neither maneuver was successful in rescuing the impaired homing of 48-hour- cultured $\mathrm{CD}_{3} 4^{+}$cells (Figure 5Bi-ii). In separate experiments, we confirmed that ZB4 was able to inhibit the apoptosis of Jurkat $\mathrm{T}$ cells triggered by FasL (data not shown).

\section{Effect of SDF-1 and of retronectin on the homing of cytokine-activated $\mathrm{CD} 34^{+}$cells}

Alterations in homing and engraftment may be dependent on the particular culture conditions used. Including IL-3 in stimulation cultures may be detrimental to the engraftment potential of expanded cells. ${ }^{19}$ Omitting IL-3 from our cultures had no significant effect on the homing behavior of cytokine-activated cells (Figure 6A). Recent reports suggest that, in addition to its chemotactic properties, SDF-1 may also be important in the survival and cell cycle behavior of $\mathrm{CD} 4^{+}$cells. ${ }^{22,23}$ Exposing 4-day-activated $\mathrm{CD} 4^{+}$cells to SDF-1 for another 2 days increased the proportion of cells in $\mathrm{G}_{0} \mathrm{G}_{1}$ (from $72 \%$ to $85 \%$ ) but had no effect on homing behavior (Figure 6B). Finally, culture on retronectin has been reported to result in superior engraftment potential. $^{21}$ We included retronectin in our standard cytokine culture or took 4-day-cultured $\mathrm{CD} 4^{+}$cells, washed them, and replated them on retronectin in the presence of SCF and then tested for BM homing ability in conditioned animals. We did not find that either of these culture methods using retronectin was able to restore the homing levels of cytokine-activated CD $34^{+}$cells (Figure 6B).

\section{Discussion}

A major finding reported here is that the reduced engraftment of cytokine-activated adult human $\mathrm{CD} 4^{+}$cells is associated with a marked alteration in homing behavior. We show, first, that MPB CD $34^{+}$ cells cultured in serum-free medium with cytokines have reduced engraftment in vivo, which is evident by 48 hours of culture. Multilineage engraftment was demonstrated for fresh and postculture cells; the only difference was that the predominant lymphoid over myeloid engraftment by fresh CD $34^{+}$cells is not seen with postculture cells. This confirms an earlier observation from our group. ${ }^{30}$ Ex vivo culture had a striking effect on the homing behavior of $\mathrm{CD} 34^{+}$cells, resulting in a marked decrease in homing to the BM and a concomitant increase in cells localizing to the lungs. Reduced homing to the BM was evident by 24 hours and persisted for up to 5 days, with no sign of reversibility. Thus, the defect in homing and engraftment occurred rapidly after $\mathrm{CD} 4^{+}$cell exposure to cytokines, when most cells would not have divided. ${ }^{13}$ This rapid and sustained loss of engraftment potential in adult $\mathrm{CD} 4^{+}$cells after cytokine exposure is in accord with findings from another published study. ${ }^{31}$ In that study, however, the authors did not follow in parallel the changes in homing behavior. ${ }^{31}$ The levels of homing we report here for freshly isolated peripheral blood CD $34^{+}$ cells are similar to those reported by van Hennik et al, ${ }^{32}$ who quantified human CFCs and CAFCs in BM at 22 to 24 hours after injection into irradiated NOD/SCID animals. The rapid time course of the homing process is also in accord with other reports using cord blood or adult blood CD $34^{+}$cells. ${ }^{33,34}$ Kollet et $\mathrm{al}^{34}$ found that 48-hour stimulation of cord blood CD $34^{+}$cells with SCF and IL-6 increased the numbers of CFCs recovered from the BM of animals after transplantation, but they did not quantify these as a percentage of infused cells; hence, we have no information regarding the efficiency of the homing process. In this study we have demonstrated the defective homing of cytokine-stimulated human adult $\mathrm{CD} 4^{+}$cells using a functional assay for $\mathrm{CFCs}$ and a cell-tracking assay to assess total cell numbers in the BM. To exclude any 
A

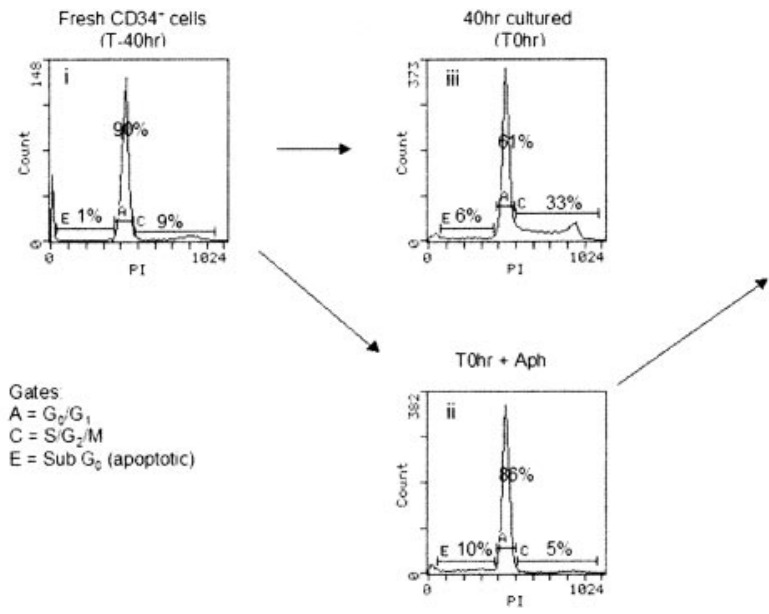

T+3hr cultured (-Aph)
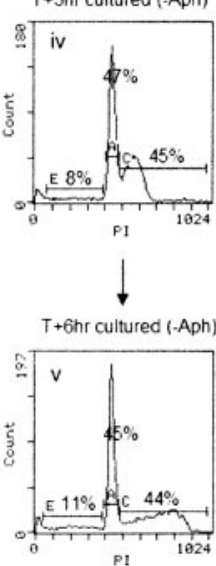

B

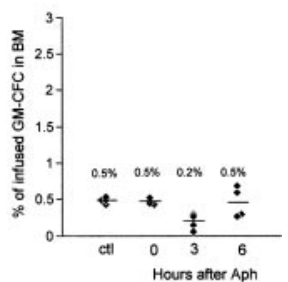

Figure 4. Effect of cell cycle synchronization on BM homing of cultured $\mathrm{CD}_{34}{ }^{+}$cells. (A) Freshly isolated $\mathrm{CD}_{34}{ }^{+}$cells reside in the $\mathrm{G}_{0} / \mathrm{G}_{1}$ phase of the cell cycle (i). Cells were stimulated with SCF, FL, or TPO for 16 hours, after which they were reversibly blocked at the $\mathrm{G}_{1} / \mathrm{S}$ transition by 24 -hour treatment with $2 \mu \mathrm{g} / \mathrm{mL}$ aphidicolin (ii) or were kept in initial conditions (iii). Aphidicolin-treated cells were washed extensively and were replated in fresh medium and cytokines to allow cell cycle progression. Cells entered the $S$ phase after 3 hours (iv) and reached $G_{2} / M$ at 6 hours (v). Cell cycle status was determined by DNA staining with PI, and the percentage of cells in the $G_{0} / G_{1}$ or $S / G_{2} / M$ phase of 1 representative experiment is shown. (B) Cell populations ii to $\mathrm{v}$, as indicated in panel A, were infused into NOD/SCID (1-2 $\left.\times 10^{6} \mathrm{cells} / \mathrm{animal}\right)$. Homing of CFCs to the BM was analyzed at 24 hours. Data are given for individual animals in 2 independent experiments as percentage homing of GM-CFCs. Mean values are represented by bars.

deleterious effect of irradiated murine BM on colony growth of expanded cells, we also cultured fresh and expanded CD34 ${ }^{+}$cells in the presence of irradiated and nonirradiated murine BM cells. There was no effect on the number of assayable progenitors (data not shown).

Many workers have observed that the reduction in engraftment potential coincides with the entry of cells into the active phases of the cell cycle $8-10$ in human and murine HSPCs. It has been suggested that homing ability and, thus, engraftment potential of cytokine-activated $\mathrm{CD} 4^{+}$cells alter during cell cycle transit and are especially impaired during $\mathrm{S} / \mathrm{G}_{2} / \mathrm{M}$ phase. Our results, however, do not support such a hypothesis. Although sorted $G_{0} / G_{1}$ cells showed slightly higher homing to the BM compared with sorted cells in $S / G_{2} / M$, this did not reach significance, and levels remained significantly lower than those seen with fresh cells. Importantly, sorted cells in different phases of the cell cycle did not show differences in engraftment. Moreover, cells induced to accumulate at the $G_{1} / S$ border by treatment with aphidicolin did not show increased homing to the BM compared with control cultured cells. The lower homing levels of cells in S-phase are interesting but do not explain the impaired BM homing of cultured cells. Our findings differ from those of Glimm et al, ${ }^{5}$ who used 5-day cultured cord blood $\mathrm{CD}_{3}{ }^{+}$cells and found that cells in $\mathrm{S}$ and $\mathrm{G}_{2}+\mathrm{M}$ were ineffective in repopulation assays. The reasons for this difference are not clear but may relate to different culture conditions and to intrinsic differences between cord and adult CD $34^{+}$cells. The effect of cytokine culture may be different for ontogenically earlier cells, such as cord and fetal HSPCs. ${ }^{24,35}$ Moreover, in this as in other studies, the engraftment of cytokine-activated cells was not compared with the levels achieved for fresh cells. Our findings on in vivo homing of cytokine-stimulated $\mathrm{CD} 34^{+}$cells also contrast with observations that the in vitro adhesive function of these cells changes with the cell cycle. Cultured CD $34^{+}$cells exhibit increased migration and reduced adhesion while in the $G_{0} / G_{1}$ phase of the cell cycle compared with cells in $\mathrm{S} / \mathrm{G}_{2} / \mathrm{M}^{13,26}$ It is clear, however, that extrapolating these in vitro observations to in vivo mechanisms, whereby circulating $\mathrm{CD} 34^{+}$cells home to the $\mathrm{BM}$, must be done with caution.

For engraftment to occur, transplanted cells must not only be able to migrate and adhere, they must survive long enough in the

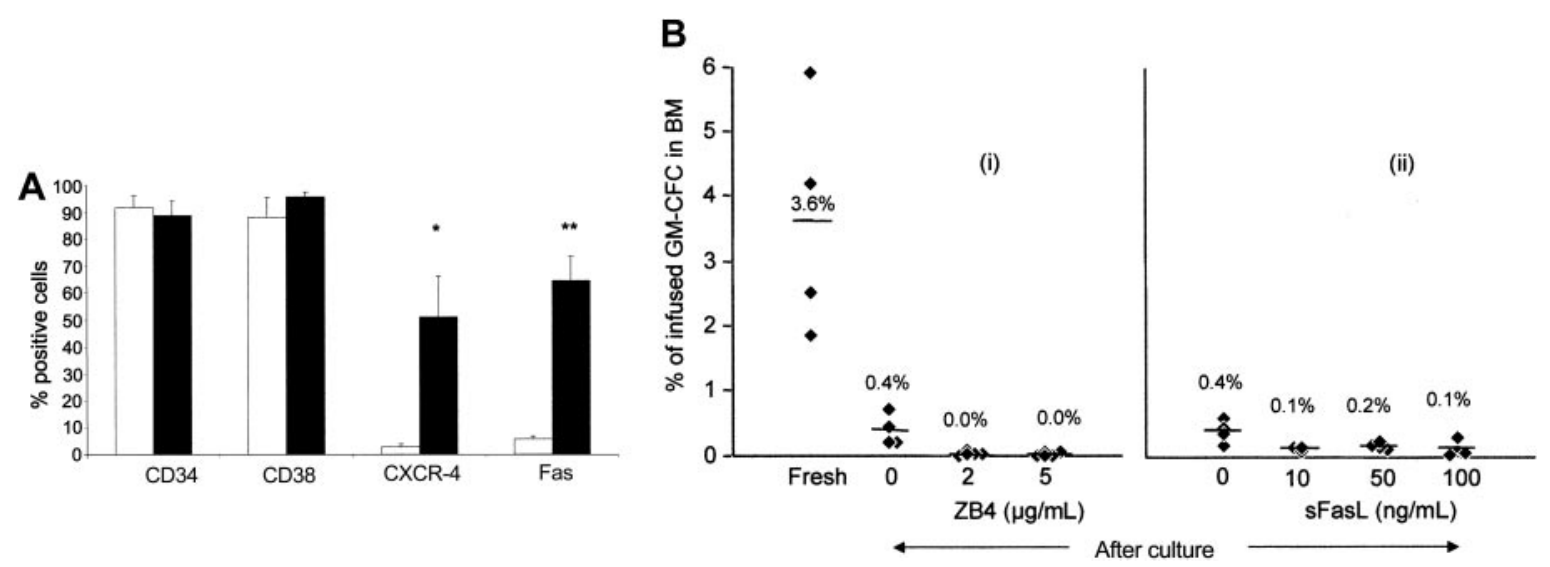

Figure 5. Role of Fas in homing of CD34+ cells. (A) Effect of cytokine exposure on the expression of surface receptors in MPB CD34+ cells. Freshly isolated CD34+ cells $(\square)$ or cultured cells (48-hour stimulation with SCF, FL [100 ng/mL] and IL-3, IL-6 [20 ng/mL]) (ロ) were stained with FITC or PE-conjugated antihuman CD34, CD38, CXCR4, and Fas/CD95 mAb and were analyzed by flow cytometry. Each bar represents the mean \pm SEM of 3 experiments $\left({ }^{*} P<.05\right.$ and ${ }^{* *} P<.01$ compared with fresh cells; Student $t$ test). (B) Blocking Fas ligation and effect on homing. Cultured CD $34^{+}$cells were pretreated with ZB4 ( 2 and $5 \mu \mathrm{g} / \mathrm{mL}$ ) for $30 \mathrm{minutes}$ (i) or were treated with sFasL at 10,50 , and $100 \mathrm{ng} / \mathrm{mL}$ (ii) before transplantation into animals $\left(2 \times 10^{6}\right.$ cells/animal). Short-term BM homing was assayed as in Figure 2 . Data are displayed as for Figure $2 \mathrm{~B}$. 
A

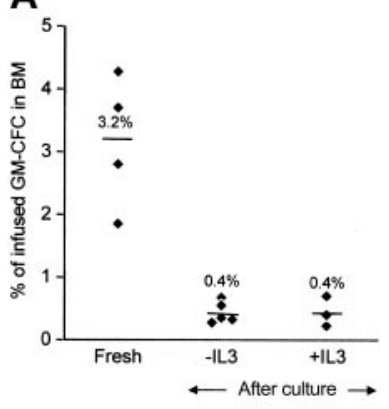

B

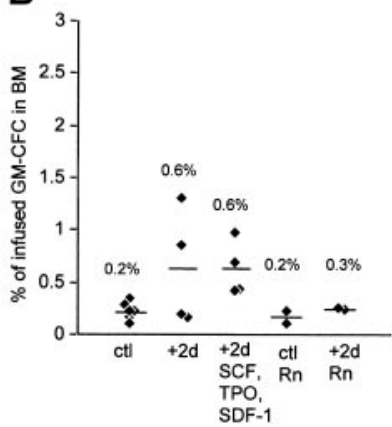

Figure 6. Effect of varying culture conditions on homing of $\mathrm{CD}_{3} 4^{+}$cells in NOD/SCID mice. (A) Freshly isolated $\mathrm{CD} 34^{+}$cells (fresh) were compared with cells stimulated in the presence or absence of IL-3, as indicated. (B) CD34 ${ }^{+}$cells were cultured for 4 days in SCF, FL, IL-3, and IL-6 with retronectin (ctl Rn) or without it (ctl). Some cells were washed and replated for another 2 days in the same cytokines $(+2 d)$ or on retronectin $(+2 \mathrm{~d} \mathrm{Rn})$ or with SDF $(+2 \mathrm{~d}$ SCF, TPO, SDF-1), as indicated. At the end of the culture period, cells were washed and injected into conditioned animals ( $2 \times 10^{6}$ cells/animal), and 24-hour BM homing of CFCs was determined. Data are displayed as for Figure 2B.

circulation to home successfully to extravascular hematopoietic niches. The results of a recent study using cultured $\mathrm{CD} 34^{+}$cells recovered from murine $\mathrm{BM} 40$ hours after infusion suggest that the defective homing of cells in the $\mathrm{S} / \mathrm{G}_{2} / \mathrm{M}$ phase results from an increased susceptibility to apoptosis. ${ }^{36}$ Here we show that Fas levels on $\mathrm{CD} 4^{+}$cells rise rapidly (by 48-72 hours) after cytokine exposure. Cytokine-activated $\mathrm{CD} 34^{+}$cells expressing high levels of Fas may undergo apoptosis in vivo on binding membrane FasL on vascular endothelium; thus, they are unable to home to the BM to secure engraftment. Indeed, the regulated expression of FasL on endothelial cells may be one mechanism whereby leukocyte extravasation is controlled. ${ }^{37}$ Our attempts to block Fas engagement on $\mathrm{CD}_{3} 4^{+}$cells using either soluble $\mathrm{FasL}^{29}$ or blocking anti-Fas $\mathrm{mAb}^{38,39}$ did not, however, lead to the restoration of homing ability in cultured $\mathrm{CD} 34^{+}$cells. Thus, it is unlikely that Fas-mediated apoptosis plays a major role in the defective homing of cytokine-activated adult cells. Since the original submission of this manuscript, Liu et $\mathrm{a}^{40}$ have shown that the homing of cultured cord blood CFCs could be restored by preincubation with Fas/CD95-blocking mAb ZB4 before transplantation. ${ }^{40}$ This difference may relate to the tissue source (cord blood) of CD34 ${ }^{+}$ cells used. ${ }^{40}$

Several investigators have attempted to restore the engraftment potential of cytokine-activated HSPCs by altering culture conditions. IL-3 is reported to enhance the loss of repopulating ability ${ }^{19}$; however, omitting IL-3 from our cultures had no effect on the reduced BM homing of cultured cells. SDF-1 is reported to induce quiescence, as is retronectin. ${ }^{21,23}$ Neither maneuver led to a recovery of homing in our system. It is important to note that the length of culture used by many of these workers was more than 48 hours and that it is not possible to discount an effect of cell division on the differentiation status of these postmitotic cells. Furthermore, though manipulating culture conditions may have a beneficial effect on engraftment in some

studies, comparison with the engraftment potential of noncultured cells was not made. Therefore, it is not possible to assess to what extent such maneuvers were actually able to reverse the engraftment defect produced by in vitro culture.

Thus, in adult CD34+ cells, cytokine-induced loss of homing to the $\mathrm{BM}$ is a phenomenon that occurs rapidly and does not appear to relate to cell cycle progression. It is also not easily explained by surface CXCR4 or Fas receptor levels or by adhesion and migration behavior in vitro. We suggest, based on our observations, an alternative explanation that takes into account the tissue distribution of infused $\mathrm{CD} 34^{+}$cells. Although migration within the $\mathrm{BM}$ and subsequent adhesion to endosteal niches are important steps in homing, it is the initial encounter with vascular endothelium that dictates the tissue destination of circulating $\mathrm{CD} 34^{+}$cells. Our previous work has shown that freshly isolated cord and adult $\mathrm{CD}_{3} 4^{+}$cells do not migrate across endothelium unless activated by cytokines, a finding subsequently confirmed by other investigators. ${ }^{41}$ This effect of cytokine stimulation on transendothelial migration applies to random and SDF-1-directed migration. ${ }^{12}$ Thus, when infused in vivo, cytokine-stimulated cells have a greater propensity to migrate out of the vasculature. This could lead to the inappropriate egress of transplanted cells into nonhematopoietic tissue. Unstimulated cells, on the other hand, have low migratory potential and only undergo transendothelial migration when stimulated by appropriate cytokines within the BM microvasculature. This would be a mechanism for the selective egress of $\mathrm{CD} 4^{+}$cells into the BM. Impaired BM homing and engraftment that occur as a result of ex vivo cytokine exposure may thus relate to changes in the tissue pattern of homing. Our finding that cytokine stimulation increases $\mathrm{CD} 34^{+}$cell localization to the lungs while reducing homing to the BM supports such a hypothesis. The increased apoptotic tendency of cytokineactivated cells may lead to the loss of any cells that migrated into nonhematopoietic tissue, thus contributing to the loss of engraftment potential in cultured cells.

In conclusion, we have demonstrated in adult $\mathrm{CD} 34^{+}$cells that cytokine exposure ex vivo leads to a loss of engraftment ability in vivo that occurs rapidly and that is associated with a striking alteration in the tissue distribution of homed cells. Loss of homing to the BM and, to a lesser extent, the spleen coincides with an increased accumulation of cells in the lungs. The loss of BM homing and engraftment is not related to the cell cycle phase and was not restored by blocking Fas ligation in vivo. We suggest that these changes in homing and, as a consequence, engraftment induced by cytokine exposure are caused by the increased migratory capacity of infused activated cells, leading to loss of selectivity of the homing process.

\section{Acknowledgment}

We are grateful to Prof D. Bonnet for help with providing murine BM.

\section{References}

1. van der Loo JC, Ploemacher RE. Marrow- and spleen-seeding efficiencies of all murine hematopoietic stem cell subsets are decreased by preincubation with hematopoietic growth factors. Blood. 1995;85:2598-2606.

2. Peters SO, Kittler EL, Ramshaw HS, Quesenberry PJ. Ex vivo expansion of murine marrow cells with interleukin-3 (IL-3), IL- 6, IL-11, and stem cell factor leads to impaired engraftment in irradiated hosts. Blood. 1996;87: 30-37.

3. Dorrell C, Gan OI, Pereira DS, Hawley RG, Dick JE. Expansion of human cord blood CD34(+) CD38(-) cells in ex vivo culture during retroviral transduction without a corresponding increase in SCID repopulating cell (SRC) frequency: dissociation of SRC phenotype and function. Blood. 2000;95:102-110.

4. Demaison C, Brouns G, Blundell MP, et al. A defined window for efficient gene marking of severe combined immunodeficient-repopulating cells 
using a gibbon ape leukemia virus-pseudotyped retroviral vector. Hum Gene Ther. 2000;11:91-100.

5. Glimm H, Oh IH, Eaves CJ. Human hematopoietic stem cells stimulated to proliferate in vitro lose engraftment potential during their S/G(2)/M transit and do not reenter $\mathrm{G}(0)$. Blood. 2000;96:4185-4193.

6. Orschell-Traycoff CM, Hiatt K, Dagher RN, et al. Homing and engraftment potential of Sca$1(+)$ lin $(-)$ cells fractionated on the basis ofadhesion molecule expression and position in cell cycle. Blood. 2000;96:1380-1387.

7. Szilvassy SJ, Meyerrose TE, Grimes B. Effects of cell cycle activation on the short-term engraftment properties of ex vivo expanded murine hematopoietic cells. Blood. 2000;95:2829-2837.

8. Gothot A, Pyatt R, McMahel J, Rice S, Srour EF. Functional heterogeneity of human CD34(+) cells isolated in subcompartments of the G0/G phase of the cell cycle. Blood. 1997;90:43844393.

9. Habibian HK, Peters SO, Hsieh CC, et al. The fluctuating phenotype of the lymphohematopoietic stem cell with cell cycle transit. J Exp Med. 1998;188:393-398.

10. Oostendorp RA, Audet J, Eaves CJ. High-resolution tracking of cell division suggests similar cell cycle kinetics of hematopoietic stem cells stimulated in vitro and in vivo. Blood. 2000;95:855-862

11. Szilvassy SJ, Bass MJ, Van Zant G, Grimes B. Organ-selective homing defines engraftment kinetics of murine hematopoietic stem cells and is compromised by ex vivo expansion. Blood. 1999 93:1557-1566.

12. Yong $\mathrm{KL}$, Watts $\mathrm{M}$, Shaun-Thomas $\mathrm{N}$, et al. Transmigration of CD $34^{+}$cells across specialized and nonspecialized endothelium requires prior activation by growth factors and is mediated by PECAM-1 (CD31). Blood. 1998;91:1196-1205.

13. Yong KL, Fahey A, Pizzey A, Linch DC. Influence of cell cycling and cell division on transendothelial migration of $\mathrm{CD} 34^{+}$cells. $\mathrm{Br} \mathrm{J}$ Haematol. 2002 119:500-509.

14. Giet O, Van Bockstaele DR, DiStefano I, et al. Increased binding and defective migration across fibronectin of cycling hematopoietic progenitor cells. Blood. 2002;99:2023-2031.

15. Yonemura Y, Ku H, Hirayama F, Souza LM Ogawa M. Interleukin 3 or interleukin 1 abrogates the reconstituting ability of hematopoietic stem cells. Proc Natl Acad Sci U S A. 1996;93:4040 4044

16. Dao MA, Hannum $\mathrm{CH}$, Kohn DB, Nolta JA. FLT3 ligand preserves the ability of human $\mathrm{CD} 34^{+}$progenitors to sustain long-term hematopoiesis in immune-deficient mice after ex vivo retroviralmediated transduction. Blood. 1997;89:446-456.

17. Luens KM, Travis MA, Chen BP, et al. Thrombopoietin, kit ligand, and flk2/flt3 ligand together induce increased numbers of primitive hematopoi- etic progenitors from human CD34+Thy- $1^{+}$Lin cells with preserved ability to engraft SCID-hu bone. Blood. 1998;91:1206-1215.

18. Danet GH, Lee HW, Luongo JL, Simon MC, Bonnet DA. Dissociation between stem cell phenotype and NOD/SCID repopulating activity in human peripheral blood CD34(+) cells after ex vivo expansion. Exp Hematol. 2001;29:1465-1473.

19. Herrera C, Sanchez J, Torres A, et al. Early-acting cytokine-driven ex vivo expansion of mobilized peripheral blood CD $34^{+}$cells generates post-mitotic offspring with preserved engraftmen ability in non-obese diabetic/severe combined immunodeficient mice. Br J Haematol. 2001;114: 920-930.

20. Wiesmann A, Kim M, Georgelas A, et al. Modulation of hematopoietic stem/progenitor cell engraftment by transforming growth factor beta. Exp Hematol. 2000;28:128-139.

21. Takatoku M, Sellers S, Agricola BA, et al. Avoidance of stimulation improves engraftment of cultured and retrovirally transduced hematopoietic cells in primates. J Clin Invest. 2001;108:447455.

22. Cashman J, Clark-Lewis I, Eaves A, Eaves C. Stromal-derived factor 1 inhibits the cycling of very primitive human hematopoietic cells in vitro and in NOD/SCID mice. Blood. 2002:99:792-799.

23. Glimm H, Tang P, Clark-Lewis I, von Kalle C Eaves $C$. Ex vivo treatment of proliferating human cord blood stem cells with stroma-derived factor- 1 enhances their ability to engraft NOD/SCID mice. Blood. 2002;99:3454-3457.

24. Wilpshaar J, Bhatia M, Kanhai HH, et al. Engraftment potential of human fetal hematopoietic cells in NOD/SCID mice is not restricted to mitotically quiescent cells. Blood. 2002;100:120-127.

25. Watts MJ, Somervaille TC, Ings SJ, et al. Variable product purity and functional capacity after CD34 selection: a direct comparison of the CliniMACS (v2.1) and Isolex 300i (v2.5) clinical scale devices. Br J Haematol. 2002;118:117-123.

26. Huygen S, Giet O, Artisien V, et al. Adhesion of synchronized human hematopoietic progenito cells to fibronectin and vascular cell adhesion molecule-1 fluctuates reversibly during cell cycle transit in ex vivo culture. Blood. 2002;100:27442752.

27. Chervenick PA, Boggs DR, Marsh JC, Cartwrigh GE, Wintrobe MM. Quantitative studies of blood and bone marrow neutrophils in normal mice. Am J Physiol. 1968;215:353-360.

28. Hendrikx PJ, Martens CM, Hagenbeek A, Keij JF, Visser JW. Homing of fluorescently labeled murine hematopoietic stem cells. Exp Hematol. 1996;24:129-140.

29. Josefsen D, Myklebust JH, Lynch DH, et al. Fas ligand promotes cell survival of immature human bone marrow $\mathrm{CD} 34^{+} \mathrm{CD} 38^{-}$hematopoietic pro- genitor cells by suppressing apoptosis. Exp Hematol. 1999;27:1451-1459.

30. Blundell MP, Demaison C, Brouns G, et al. Quality of repopulation in nonobese diabetic severe combined immunodeficient mice engrafted with expanded cord blood CD34+ cells. Blood. 1999; 94:3269-3270.

31. Young JC, Lin K, Wu S, et al. Investigating into an engraftment defect induced by culturing primitive hematopoietic cells with cytokines. Cytotherapy. 2001;3:307-320.

32. van Hennik PB, de Koning AE, Ploemacher RE. Seeding efficiency of primitive human hematopoietic cells in nonobese diabetic/severe combined immune deficiency mice: implications for stem cell frequency assessment. Blood. 1999;94:30553061.

33. Kerre TC, De Smet G, De Smedt M, et al. Both CD34(+)38(+) and CD34(+)38(-) cells home specifically to the bone marrow of NOD/LtSZ scid/scid mice but show different kinetics in expansion. J Immunol. 2001;167:3692-3698.

34. Kollet O, Spiegel A, Peled A, et al. Rapid and efficient homing of human CD34(+)CD38(-/Low) CXCR4(+) stem and progenitor cells to the bone marrow and spleen of NOD/SCID and NOD/ SCID/B2m(null) mice. Blood. 2001;97:32833291.

35. Wilpshaar J, Falkenburg JH, Tong X, et al. Similar repopulating capacity of mitotically active and resting umbilical cord blood CD34(+) cells in NOD/SCID mice. Blood. 2000;96:2100-2107.

36. Jetmore A, Plett PA, Tong $X$, et al. Homing efficiency, cell cycle kinetics, and survival of quiescent and cycling human CD34(+) cells transplanted into conditioned NOD/SCID recipients. Blood. 2002;99:1585-1593.

37. Sata M, Walsh K. TNF $\alpha$ regulation of Fas ligand expression on the vascular endothelium modulates leukocyte extravasation. Nat Med. 1998;4: 415-420.

38. Saheki K, Fujimori Y, Takemoto Y, Kakishita E. Increased expression of Fas (APO-1, CD95) on CD34 + haematopoietic progenitor cells after allogeneic bone marrow transplantation. $\mathrm{Br} \mathrm{J}$ Haematol. 2000;109:447-452.

39. Komada Y, Inaba H, Li QS, et al. Epitopes and functional responses defined by a panel of antiFas (CD95) monoclonal antibodies. Hybridoma. 1999;18:391-398.

40. Liu B, Buckley SM, Lewis ID, et al. Homing defect of cultured human hematopoietic cells in the NOD/SCID mouse is mediated by Fas/CD95. Exp Hematol. 2003;31:824-832.

41. Voermans C, Gerritsen WR, dem-Borne AE, van der Schoot CE. Increased migration of cord blood-derived CD34+ cells, as compared to bone marrow and mobilized peripheral blood CD34+ cells across uncoated or fibronectincoated filters. Exp Hematol. 1999;27:1806-1814. 